\title{
Toward a national animal telemetry network for aquatic observations in the United States
}

\author{
Barbara A. Block', Christopher M. Holbrook ${ }^{2}$, Samantha E. Simmons ${ }^{3 *}$, Kim N. Holland ${ }^{4}$, Jerald S. Ault ${ }^{5}$, \\ Daniel P. Costa ${ }^{6}$, Bruce R. Mate ${ }^{7}$, Andrew C. Seitz ${ }^{8}$, Michael D. Arendt ${ }^{9}$, John C. Payne ${ }^{10}$, Behzad Mahmoudi ${ }^{11}$, \\ Peter Moore ${ }^{12}$, James M. Price ${ }^{13}$, J. Jacob Levenson ${ }^{13}$, Doug Wilson ${ }^{14}$ and Randall E. Kochevar ${ }^{15}$
}

\begin{abstract}
Animal telemetry is the science of elucidating the movements and behavior of animals in relation to their environment or habitat. Here, we focus on telemetry of aquatic species (marine mammals, sharks, fish, sea birds and turtles) and so are concerned with animal movements and behavior as they move through and above the world's oceans, coastal rivers, estuaries and great lakes. Animal telemetry devices ("tags") yield detailed data regarding animal responses to the coupled ocean-atmosphere and physical environment through which they are moving. Animal telemetry has matured and we describe a developing US Animal Telemetry Network (ATN) observing system that monitors aquatic life on a range of temporal and spatial scales that will yield both short- and long-term benefits, fill oceanographic observing and knowledge gaps and advance many of the U.S. National Ocean Policy Priority Objectives. ATN has the potential to create a huge impact for the ocean observing activities undertaken by the U.S. Integrated Ocean Observing System (IOOS) and become a model for establishing additional national-level telemetry networks worldwide.
\end{abstract}

Background: Telemetry can provide environmental, behavioral and physiological data in near-real time, or by use of archival tags in which the data are stored or later transmitted to satellites. Aquatic animal species tagged have ranged from 6-g salmon smolts to 150-ton whales. Detailed observations of animal movements and behavior in relation to critical habitats in their aquatic environment have significantly improved our understanding of ecosystem function and dynamics. These observations are critical for sustaining populations, conserving biodiversity and implementing ecosystem-based management through an increased understanding of ecosystem structures, functions, and processes, as well as their importance to ecosystem services and values. Sensors carried by tagged animals have come of age and deliver high-resolution physical oceanographic data at relatively low costs. Animals are particularly adept at helping scientists identify critical habitats, spawning locations, and important oceanographic features (e.g., fronts, eddies and upwelling areas). They also provide important insights into regions of the oceans that are difficult and expensive to monitor (e.g., offshore environments, Arctic). This paper focuses on how to integrate an operational ATN into U.S. IOOS.

Results: The development of U.S. IOOS initially focused on the acquisition and integration of physical and chemical oceanographic data. With this system now operational, U.S. IOOS is ready to add the acquisition of relevant biological observations, and to enhance the acquisition of physical and chemical oceanographic observations via ATN platforms.

Conclusion: A U.S. ATN observing system that monitors aquatic life on a range of temporal and spatial scales could yield both short- and long-term benefits, fill oceanographic observing and knowledge gaps, and advance many of the National Ocean Policy Priority Objectives. ATN has the potential to create a huge impact for the ocean observing

*Correspondence: ssimmons@mmc.gov

${ }^{3}$ Marine Mammal Commission, Bethesda, USA

Full list of author information is available at the end of the article 
activities undertaken by $100 S$ and become a model for establishing additional national-level telemetry networks worldwide.

Keywords: Observing, Operational oceanography, Animal telemetry network, Animal-borne sensors

\section{Background}

Using animal telemetry, it is now possible to record the ocean environment and fine-scale behavior of individuals even in the most remote regions of the world's oceans, great lakes, and connecting channels. Animal telemetry is the process of obtaining data remotely (via a tag secured to the animal) and can be conducted in real time with radio and acoustic telemetry, or in 'archival mode' where logged data are stored, or downloaded from static acoustic detectors, tracks and ocean profiles are reconstructed from time-series data that are either transmitted on a time-delayed basis to satellites, or analyzed when the animal is recaptured and the tag physically returned [1-6]. Passive acoustic systems are also operational, detecting whales and dolphins based on their natural vocalizations.

Over the past two decades, thousands of animals have been tagged and released worldwide to investigate how animals use their three-dimensional world and to quantify important physical and biological aspects of their environments while in transit [7]. The tags animals carry record data at rates that may exceed one measurement per second including location, depth, temperature, light, salinity, acceleration, speed, acoustics, and physiological parameters (heart rate, oxygen, and body temperature). Animals are sensitive indicators of environmental trends and current oceanic conditions. Animal telemetry provides the opportunity to monitor these sentinels to assess current conditions and predict climate trends.

\section{Animal telemetry for resource management and conservation}

Animal telemetry data have informed federal and state fisheries management, conservation and sustainable use management policies [8,9]. For example, tag-derived movement data helped to improve management of Atlantic bluefin tuna through delineation of stock structure [10] and satellite and acoustic data from white sharks [10], combined with photo ID, are being used in models to provide estimates of California white shark populations. Patterns of habitat utilization revealed from animal telemetry have helped to identify and avoid or mitigate conflicts with oil, gas and wind development, dredging, military activities, fisheries interactions, shipping and research activities [11-20] and defining critical habitats for protected species. In Europe, tracking data from basking sharks revealed how national conservation measures were insufficient to protect this species and highlighted the need for better information about movements and habitat use of marine animals to ensure effective conservation measures [21]. Similarly, Laysan albatross tagged at Guadalupe Island, Mexico are found within the California Current System and within exclusive economic zones of at least three countries indicating that cooperative measures will be required to assure the protection of the species.

On the west coast of North America, discoveries about the unexpectedly large extent of green sturgeon movements were used to designate federally mandated critical habitat for the Endangered Species Act (ESA) listed (threatened) southern stock [12]. Similarly, animal telemetry has revealed information critical to salmon conservation in west coast river systems, e.g., that out-migrant smolt survival through the Columbia River hydropower system was better than previously believed, and that survival through the Sacramento River Basin was uniformly poor throughout the river as opposed to concentrated in the river delta [22]; in both regions, federal and state agencies spend millions of dollars per year to increase salmon survival so these are not merely academic exercises.

Information acquired through acoustic tracking has been used by government agencies to guide deployment strategies for fish aggregation devices and formulate public policy regarding responses to shark attacks and tourist activities in areas of high shark utilization $[17,20]$. Tracking data were important in the decision to list the blackfooted albatross as an endangered species by the US Fish and Wildlife Service and by BirdLife International. Such data were also essential for the development of a management plan for endangered Australian and New Zealand sea lions [23, 24].

New technology also makes it possible for tags on freeranging animals to exchange data among themselves, which can provide information on social dynamics and predator/prey interactions [5, 25]. Large marine mammals can carry mobile acoustic receivers that enable the tracking of smaller acoustic tagged animals, at times providing predator and prey information [26]. Tracking data are also essential to understanding how diseases are globally spread and how disease networks might change as animals change their migration patterns [27]. 
Animal distribution and migration data have been overlaid on oceanographic data to develop predictive mapping tools that help the US Navy avoid endangered whales, help Central Pacific longline fishers to minimize bycatch of protected loggerhead sea turtles [11], and understand the impacts of climate change on seals in the Antarctic and albatrosses in the Southern Ocean. Leatherback sea turtles have been observed to use corridors shaped by persistent oceanographic features such as the southern edge of the Costa Rica Dome and the highly energetic currents of the equatorial Pacific [28]. These findings have led to an International Union for Conservation of Nature resolution to conserve leatherback sea turtles in the open seas. Similarly, tracking data were used to develop a marine protected area (MPA) off the coast of Baja California to protect loggerhead sea turtles and to assess the efficacy of an implemented MPA to protect olive Ridley sea turtles off the coast of Gabon [16, 29].

\section{Using animals as ocean observing platforms}

In the last 25 years, technological advances have made it possible to use animals as ocean observing platforms to carry remote-sensing devices [i.e., Animal-Borne Sensors (ABS)] [3, 30-32]. ABS are mobile, autonomous platforms that are relatively inexpensive to deploy (compared to ocean gliders or AUVs), provide important insights into US coastal and EEZ areas, and are particularly useful in the open oceans that are difficult and expensive to monitor (e.g., Arctic and Antarctic regions, gyre regions). Animals are adept at finding areas of particular interest to oceanographers, including surface and sub-surface fronts, eddies, and confluences that aggregate prey. Data collected by ABS include oceanographic-quality water column profiles (temperature, conductivity, light level, oxygen, and tag-derived variables such as chlorophyll proxies from light extinction) as well as behaviors in foraging "hotspots," ecological interactions, migration routes and habitat utilization patterns. ABS complement gliders and other autonomous vehicle products to provide unique and cost-effective data from poorly sampled ocean regions, and are rapidly becoming an integral component of the Global Ocean Observing System (GOOS), especially at high latitudes. Tagged animals routinely provide vertical oceanographic profiles (Fig. 1) throughout the upper $1500 \mathrm{~m}$ of the water column and in some cases deeper $(2000 \mathrm{~m})$. Animals travel to regions that are relatively inaccessible to other ocean observing technologies, such as the polar oceans beneath seasonal or permanent sea ice [3, 30-32] or remote atolls such as those in the Northwest Hawaiian Islands. Additionally, animals move into locations and sample where Argo floats are often pushed away (upwelling zones) and across political boundaries. These data can be used to improve ocean forecasting systems by reducing initial condition errors in ocean models.

\section{Establishing a national animal telemetry network (ATN) in the United States}

The animal telemetry community is internationally recognized and organized, and large-scale global animal telemetry programs have emerged (Australian Animal Tagging and Monitoring System (AATAMS), Global

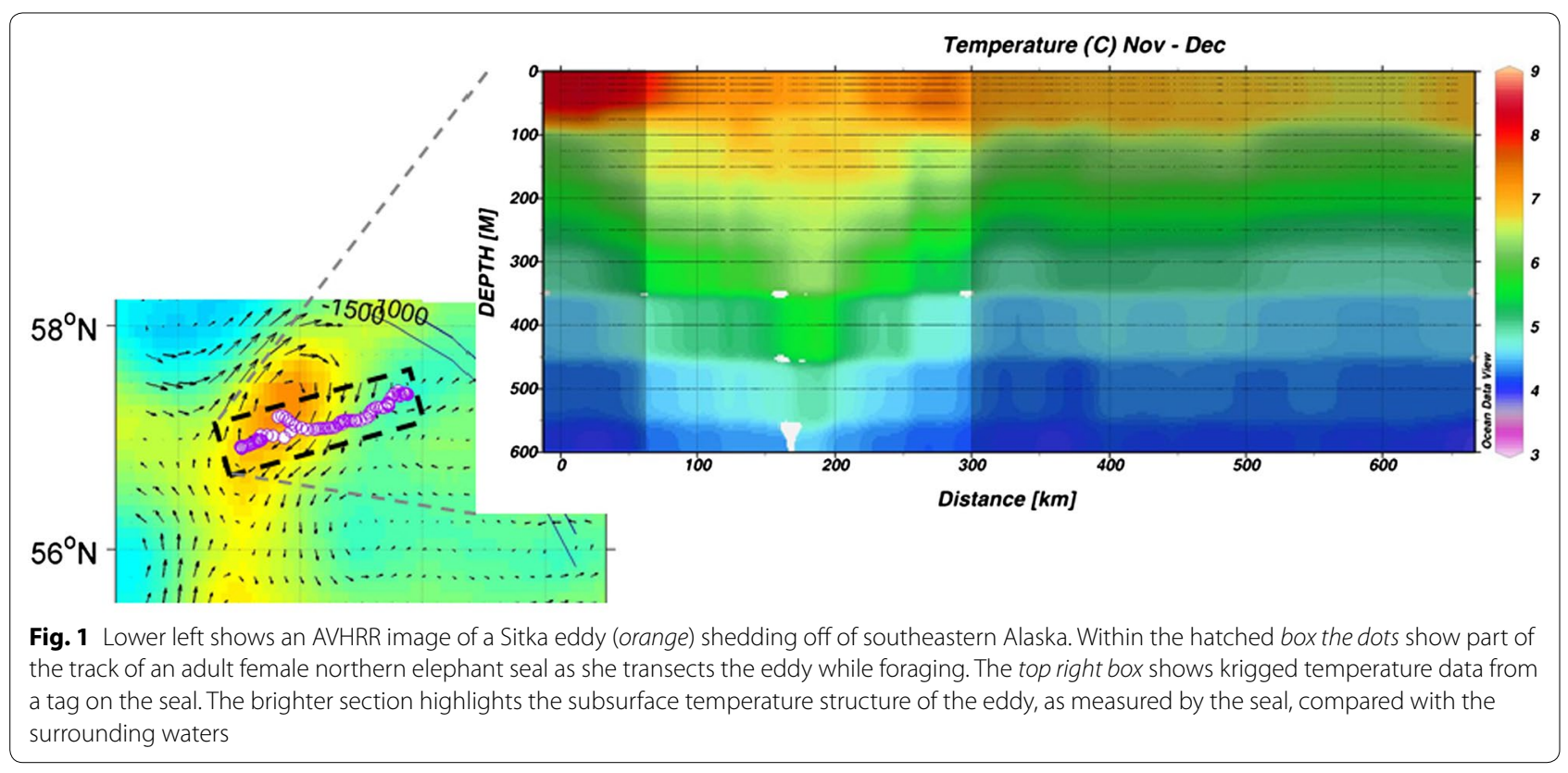


Tagging of Pelagic Predators (GTOPP), Ocean Tracking Network (OTN), Southern Elephant Seals as Oceanographic Samplers, Southern Ocean Observing System). Autonomous platforms are the backbone of the global in situ ocean observing system. An observing system that can track aquatic animals and their habitats is critical for the conservation and sustainable management of commercially harvested species, protected species and other marine resources.

Federal, state, academic and commercial organizations routinely collect animal telemetry data in the United States, but a unified, national network does not exist. Current projects range in scale from neritic to ocean basins. In the past decade, regional networks collecting data in US waters have emerged, including the Atlantic Coastal Telemetry Network, Florida Atlantic Coast Telemetry, Great Lakes Acoustic Telemetry Observation System, Pelagic Fisheries Research Program in Hawaii, Ocean Biogeographic Information System-SeaMap, Pacific Ocean Shelf Tracking, and Tagging of Pelagic Predators. Inclusion of biological resources in ocean observation is critical to advancing National Ocean Policy priority objectives, particularly Ecosystem-Based Management and Coastal and Marine Spatial Planning. Many of the existing programs already have the capability to provide live updates on animal movements, behavior, and oceanographic environment data. Importantly, demonstration projects have indicated that animal-borne sensors are reliable, inexpensive platforms for delivering high quality oceanographic data. National and international programs have succeeded in delivering these oceanographic data to the U.S. IOOS and GOOS.

We contend that aquatic resources of the U.S. would be well served by a national ATN, and that an efficient path toward developing such a network is through the U.S. IOOS. The U.S. IOOS is a national-regional partnership working to provide new tools and forecasts to improve safety, enhance the economy, and protect our environment. IOOS is a partnership of 18 Federal agencies, 11 Regional Associations (RAs), the Alliance for Coastal Technologies, and the U.S. IOOS Coastal and Ocean Modeling Test bed. The list of the U.S. IOOS federal agencies and RA partners can be found at http://www. ioos.noaa.gov.

The development of U.S. IOOS initially focused on the acquisition and integration of physical and chemical oceanographic data. With this system now operational, it is important for U.S. IOOS to add the acquisition of relevant biological data, and to enhance the acquisition of physical and chemical oceanographic data with ABS. Animal telemetry is a mature technology, provides essential information on marine resources and environmental data and is ready to be integrated within IOOS.

\section{Vision and value of a U.S. ATN through U.S. IOOS}

A national ATN through U.S. IOOS will provide integrated data on aquatic ecosystems from species to environment. This network also could complement existing ocean observing assets and inform ecosystem-based management, fisheries and biodiversity, marine planning, ocean modeling and forecasting, and United States National Ocean Policy priority objectives.

Core principles of the ATN:

- An observing system that can track aquatic animals and their habitats is critical for the conservation and sustainable management of commercially harvested species, protected species and other marine resources.

- A multidisciplinary approach is the only way to address the problems confronting aquatic species conservation and management.

- Shared data structures for biological and ocean data will facilitate multidisciplinary work of physical oceanographers and biological scientists.

To achieve a collective vision of sustainable marine resource use and conservation, a national ATN would work to meet the biological and environmental monitoring needs of multiple end-users, including (1) Federal and state agencies; (2) fisheries, marine mammal, sea turtle and bird conservation and management communities; (3) tribal communities; (4) the energy sector; (5) the tourism sector; (6) the general public; (7) educational institutions; (8) private industry.

Potential benefits of a U.S. ATN include:

- Provide the scientific basis for marine fisheries and protected-endangered species management. This includes fisheries management as mandated under the Magnuson-Stevens Act, Ecosystem-Based Management as mandated under the United States National Ocean Policy implementation plan, and management decisions for the recovery of protected marine species, such as marine mammals, fish and turtles as mandated under the Marine Mammal Protection Act (MMPA) and ESA. The ATN will provide near-real-time geospatial data integral to realistic parameterization of spatially explicit population and fishery assessment models [10]. Such models assist with the conservation of species and the maintenance of biodiversity ensuring U.S. adherence to international agreements that provide a policy framework for effective management of trans-boundary fisheries and global oceans, such as the United Nations (UN) Convention on the Law of the Sea, the UN Fish 
Stocks Agreement, and the International Convention on Biological Diversity.

- Define essential or critical habitats for species protected under the ESA and MMPA through the investigation of regional connectivity of marine biological resources and integration of ocean observation systems across large marine ecosystems, sanctuaries, and marine protected areas.

- Provide real-time monitoring of marine fish, turtles, birds, and mammals that facilitate management of marine protected areas, identification of operational windows for construction/dredging or other industrial activities, assess the impact of major environmental events, and the enforcement of fisheries regulations, to avoid harming sensitive stocks and to improve fisheries harvests.

- Evaluate the potential effects of anthropogenic disturbances. ATN will provide the critical baseline for behavior and movement of aquatic species that will aid agencies and industries that are required to assess the impact of their activities (e.g., coastal/estuarine/ riverine development, ocean thermal energy conversion and wind farm energy development, aquaculture sites, military activities, shipping, sewage treatment facilities, and marina development) under U.S. environmental regulations.

- Improve coupled ocean-atmosphere observation and forecasting models. Animal telemetry provides large volumes of oceanographic water column profiles (temperature, conductivity, light level, oxygen, chlorophyll), and complements gliders and other autonomous vehicle products to provide unique and cost-effective data from poorly sampled ocean regions. ATN data will also provide increased understanding of ecosystem processes and improve predictions of future ecosystem conditions including storms, floods, drought, climatic variation and other weather.

\section{State of the animal telemetry observing system and technology in the U.S}

In the past two decades, rapid advances in animal transmitters and data storage tags have made it possible to collect high-quality biological and oceanographic observations from animals in their habitats $[7,33,34]$. Currently, a plethora of tag types exists with distinct position and sensor capabilities. Sharks, tunas, salmon, sturgeon, marine mammals, reptiles and seabirds have been tagged routinely with sophisticated instruments that sample biological behaviors (diving), oceanographic variables (pressure, light, temperature, salinity), position (GPS, ARGOS, Geolocation) and biology/physiology (body temperature, heart rate, blood or tissue oxygen saturation, tail-beat, sound) (Fig. 2). Some of these electronic tags report profiles of the water column to satellites in near-real time. When animals predictably return to specific locations (e.g., marine mammal haul out sites), where exploitation rates are high (e.g., tunas), or where aggregation occurs around buoys (e.g., fish aggregation devices), entire archived time series can be downloaded from recovered tags. Together, these technologies provide the means to track animals for multiple years, providing seasonal, annual and climatological data. Animal telemetry provides unique datasets for resource management and ocean modelers and enables IOOS to conduct analyses that can advance many of the United States National Ocean Policy Priority Objectives.

In addition to electronic tags that record data from environmental sensors, some tags transmit acoustic data to underwater receivers. This results in a cable-free underwater network for recording animal movements and is particularly useful for studying small species, and aquatic species that do not surface often, making radio telemetry difficult to employ [5]. Decreasing size, longer battery life, and increasing sophistication of acoustic transmitters [6] provide a mechanism for monitoring the behavior of a wide range of species across great distances, using networks of underwater receivers that span multinational boundaries. Complementing these networks is the emerging use of satellite-enabled acoustic receivers and unmanned mobile gliders or mobile marine mammals fitted with acoustic receivers. For cetaceans that vocalize, passive receivers on moorings use hydrophones to listen for whales. By investing and maintaining fixed underwater receiver networks (passive and active), and mobile receiver platforms that uplink to Iridium satellite receivers or cell networks, the opportunity for long-term monitoring has emerged. Monitoring marine species is valuable not only in terms of increasing the perceived value of protected and exploited resources and minimizing human impacts, but also for the data those species deliver as roving reporters about the oceans, our changing climate and by extension our terrestrial weather. Several nations have increased the priority of using these operational technologies with substantial government and private investments (Australia: AATAMS, Canada: OTN).

Significant infrastructure costs are required for largescale acoustic telemetry. Other Nations have recognized the need for National investment in ocean infrastructure for biological monitoring and have incorporated these infrastructure costs into their growing IOOS equivalent capacities (Australia, Canada). We envision that the ATN efforts in the US would require a combination of acoustic, satellite and archival technologies deployed simultaneously that would assure complete monitoring of coastal 

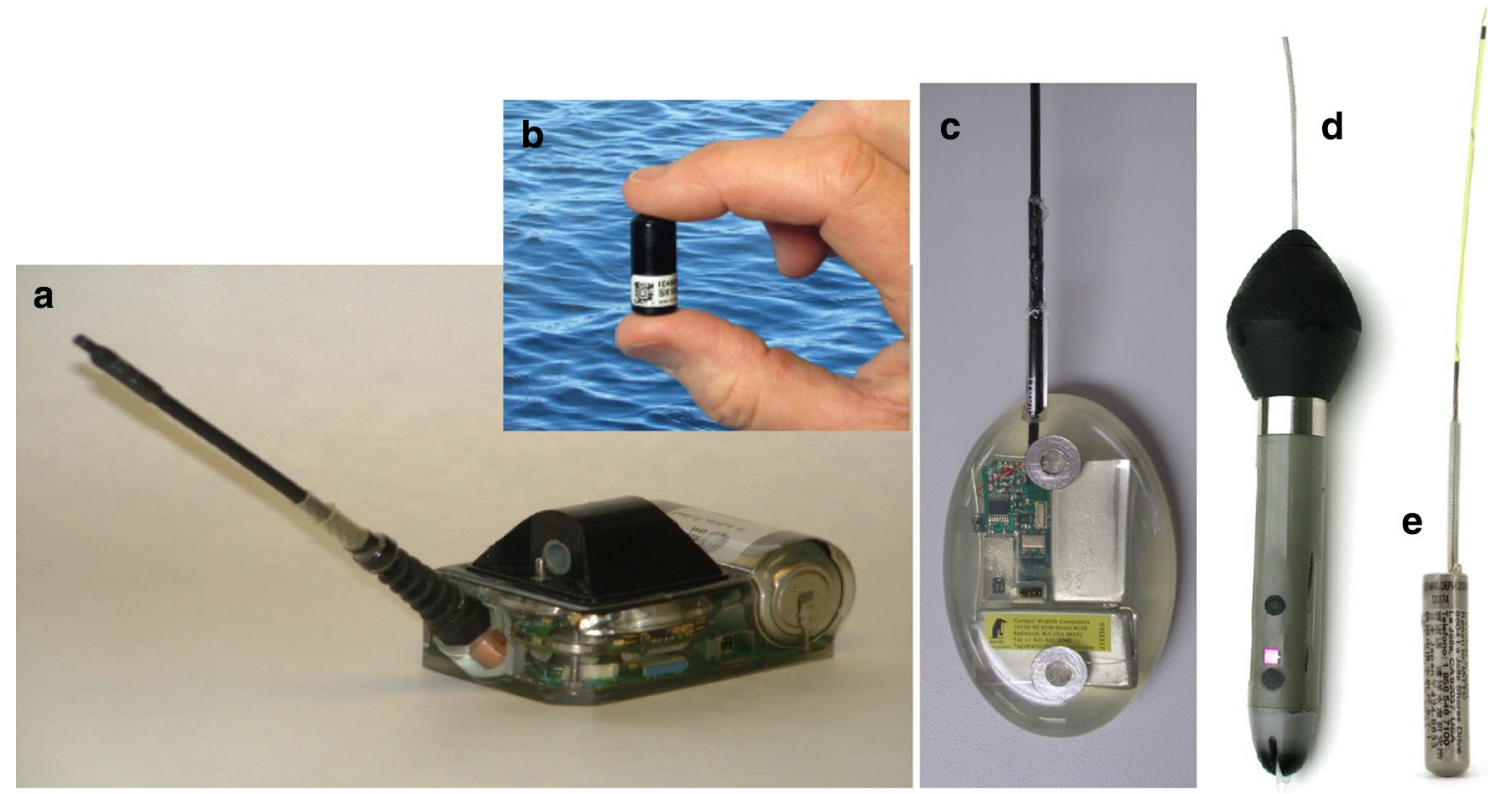

Fig. 2 Animal telemetry tags come in a variety of shapes and sizes, offering different functionalities and deployment options, here are a few examples. a Sea Mammal Research Unit Satellite Relay Data Logger, which records summaries of diving behavior and environmental data (temperature, salinity, fluorescence depending on the configuration) and can transmit a subset of those via satellite. Usually deployed on larger animals that surface regularly. b Vemco acoustic pinger (V9 model pictured) transmit unique ID codes to underwater receivers when a tagged animal passed within range (typically ranging 100-2000 m) of a receiver. Popular for coarse-scale tracking over large areas or fine-scale 'positional'tracking over small areas in both marine and freshwater environments. Optional sensors provide temperature, depth, or acceleration. Tags can operate for weeks to years depending on size and programming options. $\mathbf{c}$ Wild life Computers satellite position only tag (SPOT), initial versions of this tag provided locations only which were calculated by triangulation of transmissions to satellites. More recent versions can also collect and transmit behavioral and temperature data. Available in a variety of physical configurations so can be deployed on many different species (from fish to whales and sea lions). d Wild life Computers Pop-up Archival Tag (PAT). This tag records behavioral and environmental data as long as a corrodible link keeps it attached to the animal. When that breaks it floats to the surface and for the next $\sim 10$ days it transmits as much of the archived data as it possible. Most frequently used on larger fish species, e.g., sharks and tuna e Lotek archival tag, which records depth, temperature and on this version the long stalk is a light level sensor. The tag must be recovered to get the data. Most frequently used in harvested fish with rewards offered for recovery through commercial fisheries

and pelagic marine ecosystems within and beyond the EEZ. Importantly, US scientists are proven leaders in ATN and have organized and carried out some of the largest telemetry programs in global ocean waters $[5,22,35]$.

\section{Challenges}

The challenges lie in defining what biological ocean observing data will best meet the needs of multiple users, and discerning the most economical acquisition and delivery of ATN data to IOOS. Importantly, the technical achievements of the past decade make biological ocean observation of animals a reality, and a US operational capacity only requires stable investments in existing technology across American waters. We envision national IOOS and RA coordination and investments are required to make an ATN operational in US waters. However, due to the existence of a large number of animal telemetry regional projects, in US waters, and the coordination exemplified by ATN members at workshops to date, we believe that the rapid assembly of a unified US network is possible.

\section{Toward integration within the U.S. and internationally}

Stronger ATN ocean observing capabilities would augment our knowledge and understanding of ocean ecosystems and our ability to engage in science-based decision-making and ecosystem-based management. By developing, maintaining and disseminating an integrated data display and storage of animal and telemetry data gathered by private, academic, local, state and federal institutions, IOOS has the capacity to lead and strengthen our national ocean observing capabilities in this area. The ATN is currently a grassroots organization at a national level and IOOS is poised to take a leadership role nationally and internationally.

By taking the following steps, existing efforts could be integrated into a national ATN and ultimately become 
part of a global system for delivering critical information on biological resources and ecosystem function, and deliver oceanographic data that can complement and enhance existing observing capability:

- Invest, deploy and maintain key assets (tags, underwater receivers and data management systems) across U.S. waters. Invest in and coordinate deployment and maintenance of coastal and ocean arrays.

- Improve the national ATN data management capacity by establishing standards and infrastructure and leverage existing resource knowledge in data management to advance all regions. This will also facilitate interoperability with other national telemetry systems (AATAMS) and international efforts (OTN).

- Synthesize and make animal telemetry products available to advance U.S. ocean priorities, e.g., the National Ocean Policy priority objectives like Ecosystem-based Management, Coastal and Marine Spatial Planning.

- Advance the National capacity for making animal oceanographic telemetry data accessible in near-realtime via the Global Telecommunications System.

- Establish the capacity to assimilate ATN data daily to the ocean modeling community (HYCOM, ROMS).

- Establish pathways for rapid sharing and maintaining data at national and international levels to avoid duplication of ATN efforts and ensure data are compatible and accessible for analyses and assimilation by computer models and to improve our ability to provide accurate forecasts and inform ecosystem-based coastal and marine spatial planning.

- Promote development of lower cost tag technology.

- Promote investment in new sensors (e.g., oxygen and $\mathrm{pH}$ sensors) in response to growing concerns about the potential impacts of ocean acidification and hypoxia on marine biological resources and the health of marine ecosystems.

- Coordinate deployments of receivers and tags to reduce costs.

- Expand animal telemetry outreach and education programs toward schools, aquariums, and other institutions to foster a public understanding of the value of the ocean, coasts and the ocean observing systems.

\section{Conclusions}

Within the US ATN community discussions of data quality standards, interoperability, portability and scalability have been initiated and some demonstration projects have been funded. Increased engagement with the IOOS RAs and the establishment of a governance structure will facilitate the establishment of a sustained network.
Connections with other national and international telemetry systems/networks perhaps, initially through development or discussion of common data standards and data management practices, are essential to the continued growth of a U.S. ATN.

A U.S. ATN observing system that monitors aquatic life on a range of temporal and spatial scales could yield both short- and long-term benefits, fill oceanographic observing and knowledge gaps, and advance many of the National Ocean Policy Priority Objectives. ATN has the potential to create a huge impact for the ocean observing activities undertaken by IOOS and become a model for establishing additional national-level telemetry networks worldwide.

\section{Authors' contributions}

All authors contributed to discussions about, and development of, the manuscript describing the needs and benefits of a National Animal Telemetry Network. BB, RK, CH and SS lead the drafting of and revisions to the manuscript. All authors read and approved the final manuscript.

\section{Author details}

${ }^{1}$ Hopkins Marine Station, Stanford University, Pacific Grove, USA. ${ }^{2}$ USGS/ Great Lakes Science Center, Ann Arbor, USA. ${ }^{3}$ Marine Mammal Commission, Bethesda, USA. ${ }^{4}$ Hawaii Institute of Marine Biology, University of Hawaii, HonoIulu, USA. ${ }^{5}$ Rosenstiel School of Marine and Atmospheric Science, University of Miami, Miami, USA. ${ }^{6}$ University of California Santa Cruz, Santa Cruz, USA.

${ }^{7}$ Marine Mammal Institute, Oregon State University, Corvallis, USA. ${ }^{8}$ University of Alaska Fairbanks, Fairbanks, USA. ${ }^{9}$ South Carolina Department of Natural Resources, Charleston, USA. ${ }^{10}$ Blue Dot Research, LLC, Seattle, USA. ${ }^{11}$ Florida Fish and Wildlife Research Institute, St. Petersburg, USA. ${ }^{12}$ Mid-Atlantic Regional Association Coastal Ocean Observing System (MARACOOS), Newark, USA. ${ }^{13}$ Bureau of Ocean Energy Management, Sterling, USA. ${ }^{14}$ Caribbean Wind LLC, Baltimore, USA. ${ }^{15}$ Oceans of Data Institute, Education Development Center, Waltham, USA.

\section{Acknowledgements}

This manuscript was greatly improved by discussions with and contributions from Michael Weise, Sean Hayes, Hassan Moustahfid, John Kocik, Steven Lindley, and the feedback of two anonymous reviewers. This article is contribution 1992 of the USGS Great Lakes Science Center.

\section{Competing interests}

The authors declare that they have no competing interests.

\section{Disclaimer}

Any use of trade, product, or firm names is for descriptive purposes only and does not imply endorsement by the US Government.

Received: 28 April 2015 Accepted: 2 November 2015

Published online: 03 February 2016

\section{References}

1. Arnold G, Dewar H. Electronic tags in marine fisheries research: a 30-year perspective. In: Seibert J, Nielsen J, editors. Electronic tagging and tracking in marine fisheries. Dordrecht: Kluwer Academic Publishers; 2001. p. 7-64

2. Gunn J, Block BA. Advances in Acoustic, archival and satellite tagging of tunas. In: Block BA, Stevens ED (eds) Tuna: physiology, ecology, and evolution, 2001-Elsevier. 2001.

3. Fedak M, Lovell P, McConnell B, Hunter C. Overcoming the constraints of long range radio telemetry from animals: getting more useful data from smaller packages. Integr Comp Biol. 2002;42(1):3-10. 
4. Johnson MP, Tyack PL. A digital Acoustic recording tag for measuring the response of wild marine mammals to sound. IEEE J Ocean Eng V. 2003;28:3-13.

5. Welch D, Boehlert GW, Ward R. POST: The pacific ocean tracking project. Oceanol Acta. 2003;25:243-53.

6. Holland KN, Meyer CG, Dagorn LC. Inter-animal telemetry: results from first deployment of acoustic 'business card' tags. Endangered Species Res. 2009. doi:10.3354/esr00226.

7. Hussey NE, Kessel ST, Aarestrup K, Cooke SJ, Cowley PD, Fisk AT, Harcourt RG, Holland KN, Iverson SJ, Kocik JF, Mills Flemming JE, Whoriskey FG. Aquatic animal telemetry: a panoramic window into the underwater world. Science. 2015;348(6240):1255642.

8. Moore AM, Arango HG, Broquet G, Edwards C, Veneziani M, et al. The regional ocean modeling system (ROMS) 4- dimensional variation data assimilation systems: Part II-Performance and application to the California Current. Prog Oceanography. 2011;91:50-73.

9. Moore AM, Arango HG, Broquet G, Edwards C, Veneziani M, et al. The regional ocean modeling system (ROMS) 4-dimensional variational data assimilation systems: Part III. Observation impact and observation sensitivity in the California Current System. Prog: Oceanography; 2011. doi:10.1016/j.pocean.2011.05.005.

10. Taylor N, McAllister M, Lawson G, Carruthers T, Block BA. Model for assessing population biomass. PLOS ONE. 2011;6:e27693. doi:10.1371/journal. pone.0027693.

11. Howell EA, Kobayashi DR, Parker DM, Polovina JJ. TurtleWatch: a tool to aid in the bycatch reduction of loggerhead turtles Caretta caretta in the Hawaii-based pelagic longline fishery. Endang. Sp. Res. 2008;5:267-78.

12. Lindley ST, Moser MM, Erickson DL, Belchik M, Welch DW, Rechiski E, Klimley AP, Kelly JT, Heublein JC. Marine migration of North American green sturgeon. Trans Am Fish Soc. 2008;137:182-94.

13. Perry RW, Brandes PL, Michel CJ, Klimley AP, MacFarlane RB, Skalski JR. Sensitivity of survival to migration routes used by juvenile Chinook salmon to negotiate the Sacramento-San Joaquin River Delta. Environ Biol Fishes. 2013;96:381-92.

14. Michel CJ, Ammann AJ, Chapman ED, Sandstrom PT, Fish HE, Thomas MJ, Singer GP, Lindley ST, Klimley AP, MacFarlane RB. The effects of environmental factors on the migratory movement patterns of Sacramento River yearling late-fall run Chinook salmon (Oncorhynchus tshawytscha). Environ Biol Fishes. 2013;96:257-71.

15. Perry RW, Skalski JR, Brandes PL, Sanstrom PT, Klimley AP, Ammann A, MacFarlane B. Estimating Survival and Migration Route Probabilities of Juvenile Chinook Salmon in the Sacramento-San Joaquin River Delta. North Am J Fish Manag. 2010;30(1):142-56.

16. Peckham SH, Maldonado D, Walli A, Ruiz G, Nichols WJ, et al. Small-scale fisheries bycatch of Pacific loggerheads can rival that in large-scale oceanic fisheries. PLoS Biology ONE. 2007;2:1-6.

17. Meyer CG, Dale JJ, Papastamatiou YP, Whitney NM, Holland KN. Seasonal cycles and long-term trends in abundance and species composition of sharks associated with cage diving ecotourism activities. Environ. Cons. 2009;36(2):1-8.

18. Tyack PL, Zimmer WMX, Moretti D, Southall BL, Claridge DE, et al. Beaked Whales Respond to Simulated and Actual Navy Sonar. PLoS ONE. 2011;6:e17009.

19. J.F. Kocik, J.P. Hawkes, T.F. Sheehan, P.A. Music \& K.F. Beland (2009) Assessing estuarine and coastal migration and survival of wild Atlantic salmon smolts from the Narraguagus River, Maine using ultrasonic telemetry. In Haro, A. J., et al., editors. Challenges for Diadromous Fishes in a Dynamic Global Environment. American Fisheries Society Symposium 69. Bethesda, Maryland. pp 293-310.
20. Holland KN, Wetherbee BM, Lowe CG, Meyer CG. Movements of tiger sharks (Galeocerdo cuvier) in coastal Hawaiian waters. Mar Biol. 1999;134:661-73.

21. Southall EJ, Sims DW, Witt MJ, Metcalfe JD. Seasonal Space-Use Estimates of Basking Sharks in Relation to Protection and Political-economic Zones in the North-East Atlantic. Biol Conserv. 2006;132(1):33-9. doi:10.1016/j. biocon.2006.03.011.

22. Payne JC, et al. Tracking fish movements and survival on the Northeast Pacific Shelf; pp. In: McIntyre A, editor. Marine Life: Diversity. Wiley Blackwell, London: Distribution and Abundance; 2010. p. 269-90.

23. Campbell RA, Chilvers BL, Childerhouse S, Gales NJ Conservation management issues and status of the New Zealand (Phocarctos hookeri) and Australian (Neophoca cinerea) sea lion, Pages 455-469. In: Trites AW, Atkinson SK, DeMaster DP, Fritz LW, Gelatt TS, Rea LD, Wynne KM (eds) Sea Lions of the World. 2006.

24. Hamer DJ, Goldsworthy SD, Costa DP, Fowler SL, Page B, Sumner MD. Impact of demersal shark gill-nets on endangered Australian sea lions in South Australia: spatial overlap of fishing and foraging effort and level of by-catch mortality. Biol Conserv. 2013:157:386-400

25. Guttridge TL, Gruber SH, Krause J, Sims DW. Novel acoustic technology for studying free-ranging shark social behaviour by recording individuals' interactions. PLoS ONE. 2010;5(2):e9324. doi:10.1371/journal. pone.0009324.

26. Hayes SA, Teutschel NM, Michel CJ, Champagne C, Robinson PW, Yack T, Mellinger D, Simmons S, Costa DP, MacFarlane RB. Mobile receivers: releasing the mooring to 'see' where fish go. Environ Biol Fishes. 2011. doi:10.1007/s10641-011-9940-x

27. Goldstein T, Mazet JAK, Gill VA, Doroff AM, Burek KA, Hammond JA. Phocine Distemper Virus in Northern Sea Otters in the Pacific Ocean, Alaska. USA. Emerging Infectious Diseases. 2009;15(6):925-7. doi:10.3201/ eid1506.090056.

28. Shillinger GL, Palacios DM, Bailey H, Bograd SJ, Swithenbank AM, Gaspar P, Wallace BP, et al. Persistent leatherback turtle migrations present opportunities for conservation. PLoS Biol. 2008;6:e171.

29. Maxwell SM, Breed GA, Nickel BA, Makanga-Bahouna J, Pemo-Makaya E, et al. Using satellite tracking to optimize protection of long-lived marine species: olive ridley sea turtle conservation in Central Africa. PLOS ONE. 2011;6:e19905.

30. Biuw M, Boehme L, Guinet C, Hindell M, Costa DP, Charrassin J-B, Roquet F, Bailleul F, Meredith M, Thorpe S, Tremblay Y, McDonald B, Park Y-H, Rintoul S, Bindoff N, Goebel M, Crocker D, Lovell P, Nicholson J, Monks F, Fedak MA. Variations in behavior and condition of a Southern Ocean top predator in relation to in situ oceanographic conditions. PNAS. 2007; 104:13705-10.

31. L. Boehme, M. A. Fedak, et al. Biologging in the global ocean observing system. In proceedings of the "OceanObs'09. Sustained Ocean Observations and Information for Society." Conference vol. 2, 21-25 (Hall, J. Harrison DE, Stammer, D, eds) (Venice, Italy September 2009) 2009.

32. Costa DP, Crocker DE, Goebel ME, Fedak MA, McDonald BI, Huckstadt LA Climate change and habitat selection of seals in the western antarctic Peninsula. Integr Comp Biol. 2010;50:1018-30.

33. Cooke SJ, Hinch SG, Wikelski M, Andrews RD, Kuchel L, Wolcott TG, Butler PJ. Biotelemetry: a mechanistic approach to ecology. Trends Ecol Evol. 2004;19(6):334-43.

34. Rutz C, Hays GC. New frontiers in biologging science. Biol Lett. 2009;5(3):289-92.

35. Block BA, Jonsen ID, Jorgensen SJ, Winship AJ, Shaffer SA, et al. Tracking apex marine predators in a dynamic ocean. Nature. 2011;475:86-90. 